\title{
A quem deve servir o conhecimento?
}

A Id on line REVISTA DE PSICOLOGIA, chega ao número 27. Uma trajetória de quase uma década. Isso representa um acervo próximo de 300 artigos, disponíveis na plataforma institucional deste Periódico. Tal iniciativa torna acessível toda essa produção. Esperamos muito em breve poder potencializar o acesso aos conteúdos aqui publicados, disponibilizando-os em um número cada vez maior de bases de dados importantes.

Esta edição traz na primeira sessão, três artigos na área da educação. O primeiro discute a "Atuação da Coordenação Pedagógica em dois Campis do Instituto Federal do Ceará". O material, de excelente qualidade, foi enviado pelos autores: Josefa Ataíde Gomes de Sousa, Maria de Fátima Morais Alves, Márcia Leyla de Freitas Macêdo Felipe e, José Willame Felipe Alves. Um rico trabalho com informações que podem servir de referência para outros estudos semelhantes.

O artigo dos professores: Maria Rosângela Dias Pinheiro, Lucas Vieira de Lima Silva, Nilmara Serafim Chagas e Janilda dos Santos Barbosa, tece considerações sobre as contribuições da Educação Física no Ensino Fundamental. Num outro trabalho, Débora dos Santos Silva e Raul Max Lucas da Costa, discutem a Relação Professor-Aluno na educação superior, à partir de uma perspectiva Psicanalítica.

Na sessão Psicologia e Saúde foram contemplados cinco trabalhos. Dentre os quais, "Atenção Básica e Ouvidoria, Um perfil da Interação população Gestão", que avalia a interação existente entre as ouvidorias e as Unidades da Estratégia de Saúde da Família, à partir do ponto de vista dos usuários, de autoria de Soleane Lavor de Almeida, Shirley Kaliny Correia de Matos, Cleidiane Barbosa Paz, Onelliany Moreira Leite Lima Santana, Ana Cristina Mortimer Lio de Carvalho e Gislene Farias de Oliveira. Outro artigo trata dos "Fatores relacionados à adesão ao Exame Papanicolau, entre mulheres de 18 a 59 anos de idade". de Soleane Lavor de Almeida, Shirley Kaliny Correia de Matos, Cleidiane Barbosa Paz, Onelliany Moreira Leite Lima Santana, Ana Cristina Mortimer Lio de Carvalho e Jailma dos Santos Barbosa.

Na sequência o interessante artigo de Sebastião Elan dos Santos Lima e Joel Lima Júnior, denominado "O Imaginário dos pacientes acerca da Doença Renal Crônica", tratando de especificidades emocionais desta enfermidade. O artigo "Representações Sociais de Doente Mental na Percepção dos Cuidadores”, de Irineide Beserra Braga, Juliana de Freitas 
ID on line REVISTA DE PSICOLOGIA

http://idonline.emnuvens.com.br/id

ISSN on-line: 1981-1179

Vasconcelos, Anny Caroline Costa Vieira e, Thércia Lucena Grangeiro Maranhão, segue a mesma linha de raciocínio.

A “ Prevalência de sintomas Osteomusculares em cobradores de ônibus coletivos em uma Empresa na Cidade de Juazeiro do Norte - CE", de autoria de Anny Caroline Costa Vieira, Cristiane Marinho Uchôa Lopes, Denise Leal Pires, Gilnara Rosana Pereira de Almeida e Gislene Farias de Oliveira, discutem e evidenciam esse tipo de enfermidade na citada categoria profissional.

$\mathrm{Na}$ sessão Administração e Recursos Humanos, um artigo merece destaque: "A Importância do Comportamento Organizacional para o alcance da Eficácia Empresarial", resultado do trabalho de Verônica Maria Neto Lopes e da Professora Fernanda Roda de Souza Araújo Cassundé, da Universidade Federal do Vale do São Francisco - UNIVASF.

Uma Revisão da literatura sobre as "Principais Patologias Orofacias recorrentes em Serviços de Urgências Odontológicas, é descrito detalhadamente por Maria Eridan Moreira de Oliveira, Patrícia Amanda da Silva Andrade de Macêdo, Tiago Gomes Norões, Jailma dos Santos Barbosa e, Evandir Florêncio Medeiros.

Também um Relato de Caso sobre "Grupo de Família", que trata dos cuidadores de um Hospital Psiquiátrico. É descrito pelos autores Anna Karinna Melo Barreto e Leda Mendes Pinheiro.

Três Commnents finalisam esta edição. Um sobre a "História e Memória da Deficiência Auditiva no Brasil", de Maria das Graças Carvalho, Maria Cristina Delmondes Nascimento e, Joelma dos Santos Barbosa Linhares Garcia; outra sobre as "Percepções das Puérperas frente ao Recém-Nascido em UTI Neonatal de um Hospital em Juazeiro do Norte - CE”, de Yáscara Mychaelle Almeida Alencar, Sara Araújo de Moraes e, Martha Maria Macedo Bezerra e, uma última sobre " Pejotização e Parasubordinação, de Francizete Amaro da Silva, Bárbara Maria de Moraes Dante Santaguida e, Athena de Albuquerque Farias, propondo uma discussão mais embasada teoricamente sobre o direito do Trabalho.

Agradecemos a todos os autores pela excelente contribuição nesta edição de n. 27 da Id on line REVISTA DE PSICOLOGIA, tanto em dossiê temático quanto em demanda contínua e, desejamos aos leitores desta publicação, que façam um ótimo proveito de seus conteúdos.

A Id on line REVISTA DE PSICOLOGIA recebe continuamente material de professores, e pesquisadores para a sua demanda de artigos, podendo os mesmos serem 
ID on line REVISTA DE PSICOLOGIA

http://idonline.emnuvens.com.br/id

ISSN on-line: 1981-1179

submetidos através do Portal próprio (http://idonline.emnuvens.com.br/id), de acordo com as orientações lá disponíveis.

Lembramos que, tão importante quanto se obter o conhecimento é saber inserir o mesmo na prática cotidiana. O acesso ao conhecimento, por si só, não é garantia de sua efetiva aplicabilidade, mas pode representar uma contribuição muitíssimo significativa nesta direção

Mas, o que fazer com toda a informações e todo o conhecimento disponibilizado? Acreditamos que caberá ao leitor mais motivado, a iniciativa deste desafio.

Mais uma vez, parabenizamos a equipe de produção deste importante periódico científico, pelos seus quase 10 anos de difusão do conhecimento científico de qualidade.

Gislene Farias de Oliveira ${ }^{1}$

Editora gerente

\footnotetext{
${ }^{1}$ Psicóloga, Doutora em Psicologia Social pela Universidade Federal da Paraíba e Pós doutorado em Ciências da Saúde pela Faculdade de Medicina do ABC - SP. É Professora Associada da Universidade Regional do Cariri - URCA ,e Professora Adjunta da Faculdade de Medicina da Universidade Federal do Cariri - UFCA. E-mail: gislenefarias@gmail.com.
} 